\title{
Neuropsychological Outcome in Perinatal Stroke Associated With Epileptiform Discharges in Sleep
}

\author{
Aleksandra Mineyko, Wei Qi, Helen L. Carlson, Luis Bello-Espinosa, \\ Brian L. Brooks, Adam Kirton
}

\begin{abstract}
Background: Patients with arterial perinatal stroke often suffer long-term motor sequelae, difficulties in language, social development, and behaviour as well as epilepsy. Despite homogeneous lesions, long-term behavioural and cognitive outcomes are variable and unpredictable. Sleep-related epileptic encephalopathies can occur after early brain injury and are associated with global developmental delays. We hypothesized that sleep-potentiated epileptiform abnormalities are associated with worse developmental outcomes after perinatal stroke. Methods: Participants were identified from a population-based cohort (Alberta Perinatal Stroke Project). Inclusion criteria were magnetic resonance imaging-confirmed arterial perinatal stroke, age 4 to 18 years, electroencephalogram (EEG) including sleep, and comprehensive neuropsychological evaluation. Sleep-related EEG abnormalities were categorized by an epileptologist blinded to the cognitive outcome. Associations between EEG classification and neuropsychological outcomes were explored $(t$ tests, Bonferroni correction for multiple comparisons). Results: Of 128 potentially eligible participants, 34 (53\% female) had complete EEG (mean age, 8.1 years; range, 0.2-16.4) and neuropsychology testing (mean age, 9.8 years; range 4.4-16.7). Twelve (35\%) were classified as having electrical status epilepticus in sleep. Patients with abnormal EEGs were more likely to have statistically worse scores when corrected for multiple comparisons, in receptive language (median, 1st percentile; IQR 1-7th percentile; $\mathrm{p}<0.05$ ), and externalizing behaviours (median, 82nd percentile; IQR, 79-97th percentile; $\mathrm{p}<0.05$ ). Conclusions: Developmental outcome in language and behaviour in children with arterial perinatal stroke is associated with electrical status epilepticus in sleep. Increased screening with sleep EEG is suggested, whereas further studies are necessary to determine if treatment of EEG abnormalities can improve outcome.
\end{abstract}

RÉSUMÉ: Évolution neuropsychologique d'enfants victimes d'AVC périnataux associés à des décharges épileptiformes pendant le sommeil. Contexte: Les nouveau-nés victimes d'un AVC ischémique résultant de l'occlusion d'une artère souffrent souvent de séquelles motrices à long terme, d'épilepsie et de difficultés sur le plan du langage, du développement social et du comportement. Malgré la présence de lésions cérébrales homogènes, l'évolution comportementale et cognitive de ces enfants demeure variable et difficile à prédire. Des cas d'encéphalopathies épileptiques liés au sommeil peuvent en effet survenir après que de telles lésions se sont produites. De tels cas seront associés à un retard général de développement. Nous avons ainsi formulé l'hypothèse suivante : que les cas d'anomalies épileptiformes potentialisés pendant le sommeil sont associés, à la suite d'un AVC périnatal, aux plus sévères retards développementaux. Méthodes: Nous appuyant sur le Alberta Perinatal Stroke Project, nous avons sélectionné nos participants à partir d'une cohorte représentative de la population. Nos critères d'inclusion étaient les suivants : avoir passé une IRM ayant confirmé un AVC périnatal résultant de l'occlusion d'une artère ; être âgé de 4 à 18 ans ; avoir passé une EEG complète, notamment durant le sommeil ; et avoir fait l'objet d'une évaluation neuropsychologique complète. Nous avons aussi demandé à un spécialiste de l'épilepsie, ignorant tout de l'évolution cognitive des participants, de classer les diverses anomalies liées à leur sommeil. Les liens existant entre cette classification et les divers types d'évolution neuropsychologique ont été ensuite analysés (tests de Student ; ajustement de Bonferroni en vue de comparaisons multiples). Résultats: Sur un total de 128 participants potentiellement admissibles, 34 (dont $53 \%$ étaient des femmes) avaient passé une EEG complète (âge moyen : 8,1 ans; étendue : 0,2 -16,4) et fait l'objet d'examens neuropsychologiques (âge moyen : 9,8 ans ; étendue : 4,4-16,7). Douze d'entre eux, soit 35\%, étaient atteints, durant leur sommeil, par l'état de mal épileptique. Les participants dont les EEG avaient révélé des anomalies étaient statistiquement plus susceptibles, une fois les ajustements de Bonferroni apportés, d'obtenir des résultats plus faibles en matière de langage dans son versant réceptif (médiane : 1er percentile; intervalle interquartile : 1er jusqu'au 7e percentile; $\mathrm{p}<0,05$ ) et de comportements externalisés (médiane : 82e percentile; intervalle interquartile : 79e jusqu'au 97e percentile; $\mathrm{p}<0,05$ ). Conclusions: Tant en ce qui concerne le langage que les comportements, les retards développementaux d'enfants victimes d'un AVC périnatal résultant de l'occlusion d'une artère sont associés à l'état de mal épileptique pendant le sommeil. Un dépistage accru au moyen d'EGG serait ainsi une avenue à explorer. Des études plus poussées sont aussi nécessaires afin de déterminer dans quelle mesure les traitements de ces anomalies peuvent améliorer l'état de santé de ces jeunes patients.

Keywords: Continuous spike and wave in slow wave sleep, electrical status epilepticus in sleep, perinatal stroke, neurodevelopment, epileptic encephalopathy

doi:10.1017/cjn.2017.29

Can J Neurol Sci. 2017; 44: 358-365

\footnotetext{
From the Section of Neurology, Departments of Pediatrics and Clinical Neurosciences (AM, LB-E, AK); Department of Pediatrics (WQ); Department of Neurosciences (HLC);

Departments of Paediatrics, Clinical Neurosciences, and Psychology (BLB), University of Calgary; Calgary, Alberta, Canada.

Received SePtember 12, 2016. Final Revisions Submitted November 15, 2016. Date of Acceptance January 4, 2017.

Correspondence to: Aleksandra Mineyko, Section of Neurology, Department of Pediatrics, Alberta Children's Hospital 2888 Shaganappi Trail NW, Calgary, AB, Canada T3B 6A8.

Email: Aleksandra.mineyko@albertahealthservices.ca
} 
Perinatal stroke, a focal vascular brain injury occurring between 20 weeks' gestation and 28 days of life, ${ }^{1}$ occurs in 1:1500 to 1:5000 live births. ${ }^{2,3}$ Neuroimaging methods of distinguishing perinatal stroke syndromes have been established, ${ }^{4}$ allowing advancement of syndrome-specific outcome research. ${ }^{4-6}$ Despite similar timing of brain injury, cognitive and behavioural outcomes vary widely, even in patients with comparable size and type of injury. ${ }^{7,8}$ Although mean cognitive function testing is average to below average across groups, severe global difficulties with behavioural and cognitive dysfunction adversely impact the lives of $10 \%$ to $20 \%$ of children. ${ }^{7-10}$ Explanations for these different outcomes are not understood and no modifiable factors have been identified.

Epilepsy occurs in $15 \%$ to $50 \%$ of perinatal stroke survivors. ${ }^{11,12}$ Epilepsy has been modestly associated with worse cognitive and developmental outcomes in two perinatal stroke studies. ${ }^{9,10}$ However, the role of epileptic activity during sleep has not been previously explored. Continuous spike-wave in slow wave sleep (CSWS) is an epileptic encephalopathy featuring electrical status epilepticus in sleep (ESES) associated with delays or regression in language, cognitive, and behavioural function. ${ }^{13}$ Many authors use the terms CSWS and ESES interchangeably, and the two descriptions are likely a spectrum of similar pathology. ${ }^{14-16}$ Original descriptions of ESES defined the electroencephalogram (EEG) abnormality as a bilaterally symmetric spike and wave discharge that occupies at least $85 \%$ of slow wave sleep and that commonly occurs in preschool children. ${ }^{17}$ Others have since recognized that focal or unilateral ESES and/or discharges present for less than $85 \%$ of the recording may also contribute to neurocognitive dysfunction. ${ }^{13,14,18,19}$ The most recent, revised terminology on epilepsy by the International League Against Epilepsy does not list diagnostic criteria for CSWS/ESES, ${ }^{20}$ and spike-wave index cutoffs continue to be debated. ${ }^{18}$ ESES and similar syndromes have been described in children with early brain injuries, particularly of the thalamus, including neonatal deep sinovenous thrombosis and hemorrhagic stroke. ${ }^{21-23}$

The objective of this study was to determine the association between the presence of ESES and developmental outcome based on formal neuropsychological scores in children with arterial perinatal stroke.

\section{MeTHODS}

\section{Population}

In this retrospective, cross-sectional study, patients with perinatal arterial ischemic stroke were identified through the Alberta Perinatal Stroke Project (APSP). Established in 2008, the APSP is a population-based registry that has enrolled all prospectively diagnosed cases since 2008. Exhaustive review of $>80$ International Classification of Diseases 9 and 10 codes were combined with imaging analysis and in-person review to confirm all retrospective cases from 1992 through 2012. Perinatal stroke diagnosis required magnetic resonance imaging (MRI) confirming ischemic perinatal stroke classified by validated methods. ${ }^{4}$ Because differing stroke syndromes have different cognitive outcomes, for the current study, only patients with arterial stroke lesions were included. These were classified as either neonatal arterial ischemic stroke (NAIS) if they presented with acute neurological symptoms within 28 days of birth and had acute infarction on MRI, or arterial presumed perinatal ischemic stroke (APPIS) if presentation occurred later in infancy or childhood (typically with congenital hemiparesis) with remote arterial infarction on MRI. Inclusion criteria for the current study were MRI-confirmed NAIS or APPIS, EEG including sleep, and neuropsychological evaluation (4 years or older). The study was approved by the institutional ethics review board (ID 21522).

\section{EEG}

Patients were included if they had at least one clinical EEG performed after the neonatal period that captured sleep. All EEG reports were interpreted by the lead investigator (AM) who classified the original reports provided by epilepsy experts. A second, certified neurophysiologist and epilepsy expert (LB-E), who was blinded to neuropsychological outcomes, performed an independent review and classification of the original studies available. EEG reports at our centre often include a description of spike and wave discharges as a frequency of less than or greater than $75 \%$ or a qualitative description of "continuous" discharges in sleep. Because CSWS can refer to the clinical syndrome of epileptic encephalopathy with ESES documented on electrophysiology, for the purpose of this study, we classified EEG as either ESES or non-ESES. ESES was determined from EEG reports as either (1) a report of spike and wave discharges occurring in $>75 \%$ of sleep or (2) the report of "continuous spike and wave" or "electrical status epilepticus in sleep." A participant was included in the ESES group if at least one EEG met these criteria.

\section{Neuropsychological Testing}

A neuropsychological test battery was performed under the supervision of a clinical neuropsychologist where clinically indicated by the patient's treating neurologist. Because these were clinical assessments, different versions of tests were used depending on the child's age (e.g. Wechsler D. Wechsler Preschool and Primary Scale of Intelligence-III if younger than age 6 years and Wechsler D. Wechsler Intelligence Scale for Children, Fourth Edition, if age 6 and older), the needs of the child, or the specific referral question. Patients younger than 4 years of age were not included because of the limited number of tests available for that age range.

Domains of interest included in this study are overall intellectual functioning, language, reasoning, visual-construction, verbal learning and memory, visual learning and memory, executive functions, and behaviour. Table 1 contains a list of tests and subtests used to address functioning organized by cognitive domain. Percentile scores based on each test's population norms were used as continuous dependent variables for each subset of tests. To reduce the influence of psychomotor speed and working memory on measures of intellectual abilities, the Canadian Wechsler General Ability Index was selected as a global estimate of intellectual functioning based on verbal and nonverbal skills. For some children, the Canadian Wechsler General Ability Index was estimated using either a two-subtest version (vocabulary plus matrix reasoning) with formulas provided by Sattler $(2001)^{24}$ or a four-subtest version (vocabulary, similarities, matrix reasoning, and block design) with proration completed by the scoring program. All children that completed the Developmental Neuropsychological Assessment-2 word generation subtest were older than 7 years of age. Children older than 8 years of age completed the Delis-Kaplan Executive Function System letter fluency category fluency subtests. 
Table 1: Neuropsychological tests used by cognitive domain of interest

\begin{tabular}{l|l}
\hline Cognitive domain & Test \\
\hline Overall intellectual functioning & WISC-IV ${ }^{\mathrm{CDN}}$ GAI \\
\hline Expressive vocabulary & WPPSI-III $^{\mathrm{CDN}}$ GAI \\
\hline & WISC-IV $^{\mathrm{CDN}}$ Vocabulary \\
\hline Letter fluency & WPPSI-III ${ }^{\mathrm{CDN}}$ Vocabulary \\
\hline & NEPSY-II Word Generation \\
\hline Receptive language & DKEFS Verbal Fluency \\
\hline Abstract reasoning & NEPSY-II Comprehension of Instructions \\
\hline & WJ-III Understanding Directions \\
\hline Visual-constructional & WISC-IV \\
\hline & WPPSI-III ${ }^{\mathrm{CDN}}$ Matrix Reasoning \\
\hline Verbal learning and memory & WISC-IV \\
\hline Visual learning and memory & WPPSI-III ${ }^{\mathrm{CDN}}$ Block Design \\
\hline & CVLT-C \\
\hline Executive functioning & CVMT \\
\hline Externalizing behaviour & CMS Faces \\
\hline & BRIEF GEC \\
\hline Internalizing behaviour & BASC-2 Externalizing \\
\hline & CBCL Externalizing \\
\hline BASC-2 & CBCL Internalizing \\
\hline
\end{tabular}

BASC-2 = Behavior Assessment System for Children, second edition; $\mathrm{BRIEF}=$ Behavior Rating Inventory of Executive Function;

$\mathrm{CBCL}=$ Child Behavior Checklist; CMS = Children's Memory Scale;

CVLT-C $=$ California Verbal Learning Test-Children's Version;

$\mathrm{CVMT}=$ Continuous Visual Memory Test; GAI = General Ability Index; DKEFS $=$ Delis-Kaplan Executive Function System; NEPSY-II = A Developmental Neuropsychological Assessment;

WISC-IV ${ }^{\mathrm{CDN}}=$ Wechsler D. Wechsler Intelligence Scale for Children, fourth edition, Canadian (ages 6-16:11); WJ-III = Woodcock-Johnson III Tests of Cognitive Abilities; WPPSI-III ${ }^{\mathrm{CDN}}=$ Wechsler D. Wechsler Preschool and Primary Scale of Intelligence, third edition (ages 4-5: 11).

\section{Statistical Analysis}

Following confirmation of normal distribution (Shapiro-Wilk test), group comparisons between those with and without ESES (independent variable) were performed across neuropsychological test scores (dependent variable) using Student $t$ tests. MannWhitney U test was used for group comparisons with non-normally distributed data. Bonferroni correction was performed to correct for multiple comparisons. Cohen's d was used to determine the effect sizes between groups. A low, medium, and large effect size was set at $d \geq 0.2,0.5$, and 0.8, respectively. SPSS for Windows, v. 19.0, was used for analysis and the significance level was set at 0.05 .

\section{RESULTS}

\section{Population}

From the APSP database, 128 potentially eligible perinatal arterial ischemic stroke patients (73 NAIS, 55 APPIS) were identified (Figure 1). Of those, 37 (32 NAIS, 5 APPIS) were excluded because they were younger than age 4 years and 29 (12 NAIS, 17 APPIS) because of a lack of adequate EEG data (neonatal or awake only). Of the remaining 62 patients (29 NAIS, 33 APPIS), 167 EEGs were reviewed, and 12 patients (19\%) were classified as having ESES. Of those, three had severe developmental delays preventing formal neuropsychology evaluation. Of the 50 participants with non-ESES EEG, 22 had neuropsychology evaluations and were included. The final study population consisted of 34 participants (12 NAIS, 22 APPIS; 53\% female). Sex did not differ between ESES versus non-ESES groups $(p>0.8)$ and between NAIS and APPIS groups $(\mathrm{p}=0.8)$. All patients had anterior circulation stroke. Side of stroke did not differ between groups. The ESES group had more participants with bilateral stroke (3 ESES, 0 non-ESES; $\mathrm{p}<0.05$ ). Clinical characteristics of the population are summarized in Table 2.

\section{EEG}

A total of 167 sleep EEG recordings were scored. All EEGs were performed for the clinical indication of seizures, events suspicious for seizures, or follow-up of previous seizures. Most children had more than one recording $(66 \%)$, with a mean of 2.7 studies. The mean age at time of EEG was 8.1 years (range, 0.2-16.4). ESES was diagnosed in at least one EEG of 12 children (19\%) who had a mean age of diagnosis of 6.1 years (range, 2.1-10.3). Three of the 12 had bihemispheric ESES on EEG, with the rest being focal. Three patients with ESES had severe global developmental delay and could not participate in formal neuropsychology testing. They were excluded from the rest of the analysis. The majority (8/12) of children were taking at least one antiepileptic drug (AED) at time of ESES diagnosis. The medications included clonazepam (1), phenytoin (1), clobazam (2), oxcarbazepine (2), levetiracetam (1), and valproic acid (2). One patient was on dual treatment (clobazam and oxcarbazepine). Twenty-two children had EEG recordings that did not meet ESES study criteria but who had neuropsychology testing (mean age at EEG, 9.0 years; range, 0.2-16.4). The EEG characteristics are presented in Table 2. Patients with ESES were more likely to have the diagnosis of NAIS than APPIS (odds ratio, 6.8; 95\% confidence interval $[\mathrm{CI}], 1.4-32.4 ; \mathrm{p}=0.009)$ and to have their sleep EEG recorded at a younger age (mean, 6.1 years; 95\% CI, 4.3-7.9 vs $9.0 ; 95 \% \mathrm{CI}, 3.9-10.1, \mathrm{p}=0.03)$.

\section{Neuropsychology}

The results of the neuropsychology assessments are illustrated in Figure 2 and Table 3. The median age at time of testing was 9.8 years (range, 4.4-16.7). Patients with ESES were significantly more likely to be taking prescribed AEDs at the time of neuropsychological testing (67\% with ESES, $18 \%$ without ESES; $\mathrm{p}<0.01)$. Evaluation of all patients with perinatal arterial stroke revealed below-average scores in all cognitive domains compared with standardization values and externalizing behaviour, internalizing behaviour, and daily executive functioning were worse than peers (higher scores on these measures suggest more difficulties). The ESES group demonstrated marked impairments in all categories, scoring at the second percentile or worse. Medium to large effect sizes were noted in domains of letter fluency, receptive language, verbal learning, abstract reasoning, visual-constructional, visual memory, verbal-motor speed, 


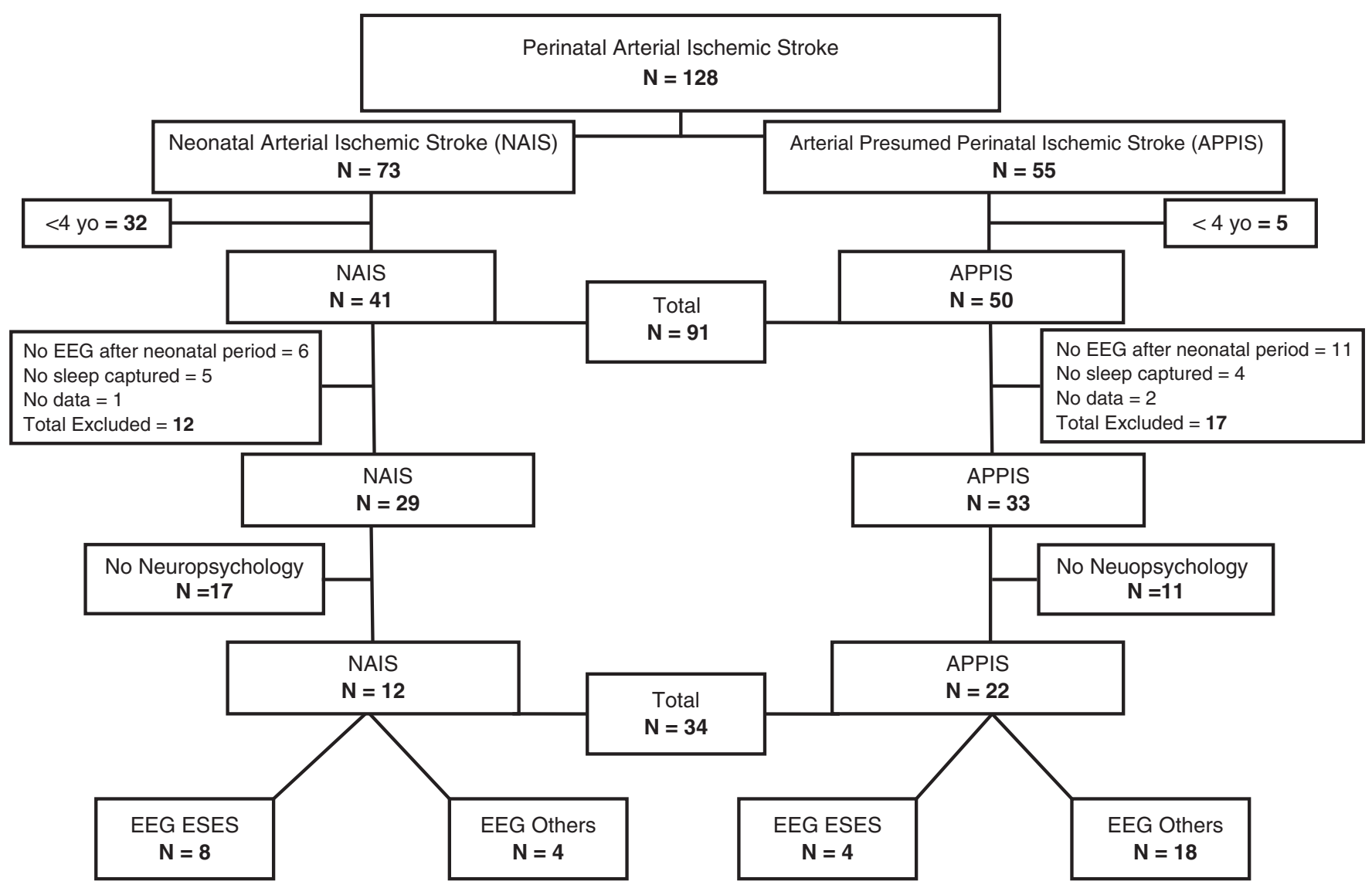

Figure 1: Study profile.

externalizing behaviours, and daily executive functioning. Statistically significant lower scores (worse performance) in receptive language, verbal learning, verbal-motor speed, visual memory, and increased scores (more problems) in externalizing behaviour were noted in the ESES group as compared with non-ESES group. When correcting for multiple comparisons, differences in receptive language and externalizing behaviours remained statistically significant with worse scores in the ESES group.

\section{DiscuSSION}

Our data suggest that children with perinatal stroke and ESES have an increased risk of neuropsychological dysfunction, particularly in receptive language and externalizing behaviours. High effect sizes in these two domains as well as in visual memory and verbal-motor speed suggest that the differences in cognitive function may be broader than our sample size can determine with statistical significance. All participants had overall lower than average neuropsychological scores in most domains consistent with a broad spectrum of previously reported cognitive outcomes in perinatal stroke. ${ }^{7,8}$

The first characterization of CSWS and ESES described a series of patients with potentiation of epileptiform discharges occupying $>85 \%$ of the slow sleep recording. This pattern persisted on a total of three EEG recordings in 1 month. ${ }^{17}$ The syndrome has been expanded in recent years to encompass patients with developmental delay or regression and marked activation of epileptiform discharges in sleep $(<85 \%)^{13,14,18,25}$ or those with unilateral or focal potentiation of epileptiform discharges with sleep. ${ }^{19,26}$ Our findings of particular deficiencies in behaviour and language development are consistent with the historical descriptions of sleep-related epileptic encephalopathies as well as studies of both lesional ${ }^{14,21-23}$ and nonlesional ${ }^{13,14,21,27}$ ESES.

There has been additional recent focus on ESES in pediatric patients with early brain injuries. In the developing brain, thalamic injuries of heterogeneous etiologies have been associated with ESES. ${ }^{21-23}$ Disruption of thalamic oscillating rhythms seen in sleep and associated with spindles has been suggested as a potential pathological mechanism for ESES. ${ }^{16}$ Patients in this study had anterior circulation ischemic strokes, which do not result in direct lesions to the thalami. It is possible that secondary thalamic injury occurs through Wallerian degeneration and atrophy following cortical ischemic injury. It is also possible that disruption of the thalamocortical connections or epileptogenic mechanisms entirely remote from the thalamus may result in ESES susceptibility. Comparative studies across these populations may yield further insight toward underlying mechanisms and perhaps aid in better identifying children at risk.

Sleep-related epileptic encephalopathy may hinder brain development. Slow wave sleep has been implicated in recuperative function and memory consolidation. ${ }^{28}$ Slow waves are hypothesized to result in a depression or downscaling of synapses in sleep. ${ }^{29}$ ESES results in a decrease in slow waves and may 
Table 2: Age of patients at time of EEG and neuropsychology testing

\begin{tabular}{|c|c|c|c|c|c|c|}
\hline Participant & Sex & $\begin{array}{c}\text { Stroke type } \\
\text { (location) }\end{array}$ & Age at EEG (years) & EEG results & Age at NT (years) & AED at NT \\
\hline 1 & $\mathrm{~F}$ & APPIS (L/R) & 2.1 & ESES & Not tested & NA \\
\hline 2 & $\mathrm{~F}$ & APPIS (R) & 5.0 & ESES & 8.2 & VPA \\
\hline 3 & M & APPIS (R) & 10.0 & ESES & 13.5 & OXC \\
\hline 4 & $\mathrm{~F}$ & APPIS (L) & 10.3 & ESES & 8.3 & CLB \\
\hline 5 & $\mathrm{~F}$ & NAIS (L) & 2.3 & ESES & Not tested & NA \\
\hline 6 & M & NAIS (L/R) & 4.0 & $\operatorname{ESES}(\mathrm{BH})$ & Not tested & NA \\
\hline 7 & $\mathrm{~F}$ & NAIS (R) & 4.2 & ESES & 4.4 & LEV \\
\hline 8 & $\mathrm{~F}$ & NAIS (L/R) & 5.5 & $\operatorname{ESES}(\mathrm{BH})$ & 6.3 & None \\
\hline 9 & $\mathrm{M}$ & NAIS (L) & 5.5 & $\operatorname{ESES}(\mathrm{BH})$ & 5.5 & None \\
\hline 10 & $\mathrm{~F}$ & NAIS (R) & 7.1 & ESES & 10.3 & VPA \\
\hline 11 & M & NAIS (L) & 7.7 & ESES & 9.8 & VPA \\
\hline 12 & M & NAIS (L) & 9.2 & ESES & 6.2 & None \\
\hline$\overline{\mathbf{x}}(95 \% \mathrm{CI})$ & F 7/M 5 & APPIS 4/NAIS 8* & $6.1(4.3-7.9)^{*}$ & & $8.1(5.9-10.2)$ & 6/9* \\
\hline 13 & M & APPIS (L) & 0.7 & FD & 4.5 & None \\
\hline 14 & $\mathrm{~F}$ & APPIS (R) & 1.1 & FD & 5.3 & None \\
\hline 15 & M & APPIS (L) & 4.1 & $\mathrm{~N}$ & 8.2 & None \\
\hline 16 & $F$ & APPIS (R) & 4.8 & $\mathrm{~N}$ & 4.5 & None \\
\hline 17 & M & APPIS (L) & 5.9 & FD & 9.4 & None \\
\hline 18 & $\mathrm{~F}$ & APPIS (L) & 7.6 & FD & 7.6 & None \\
\hline 19 & M & APPIS (R) & 8.4 & FS & 8.4 & None \\
\hline 20 & F & APPIS (L) & 9.2 & FD & 14.7 & None \\
\hline 21 & $\mathrm{~F}$ & APPIS (L) & 10.3 & FD & 16.4 & None \\
\hline 22 & M & APPIS (R) & 10.5 & FD & 10.0 & None \\
\hline 23 & $\mathrm{M}$ & APPIS (R) & 11.0 & FD & 11.5 & None \\
\hline 24 & M & APPIS (R) & 11.0 & $\mathrm{~N}$ & 11.8 & None \\
\hline 25 & $\mathrm{~F}$ & APPIS (L) & 12.3 & FD & 15.9 & None \\
\hline 26 & $\mathrm{~F}$ & APPIS (L) & 12.7 & FD & 15.9 & OXC, LEV \\
\hline 27 & $\mathrm{~F}$ & APPIS (L) & 12.9 & $\mathrm{~N}$ & 13.5 & LEV \\
\hline 28 & M & APPIS (L) & 14.0 & FD & 14.4 & None \\
\hline 29 & $M$ & APPIS (R) & 15.6 & FD & 16.7 & None \\
\hline 30 & $\mathrm{~F}$ & APPIS (L) & 16.4 & $\mathrm{~N}$ & 13.7 & $\mathrm{CBZ}$ \\
\hline 31 & $\mathrm{~F}$ & NAIS (L) & 0.2 & FS & 4.6 & None \\
\hline 32 & M & NAIS (L) & 3.8 & FD & 9.5 & None \\
\hline 33 & M & NAIS (L) & 11.1 & $\mathrm{~N}$ & 13.9 & CBZ \\
\hline 34 & F & NAIS (L) & 14.9 & FD & 14.5 & None \\
\hline$\overline{\mathbf{x}}(\mathbf{9 5} \% \mathbf{C I})$ & F 11/M 11 & APPIS 18/NAIS 4* & $9.0(3.9-10.1) *$ & & $11.1(6.6-12.7)$ & $4 / 22 *$ \\
\hline
\end{tabular}

$\mathrm{BH}=$ bihemispheric epileptiform discharge $\mathrm{CLB}=$ clobazam; $\mathrm{CBZ}=$ carbamazepine; $\mathrm{F}=$ female; $\mathrm{FD}=$ focal epileptiform discharges; $\mathrm{FS}=$ focal slowing; $\mathrm{L}=$ left; $\mathrm{LEV}=$ levetiracetam; $\mathrm{L} / \mathrm{R}=$ both left and right; $\mathrm{M}=$ male; $\mathrm{N}=$ normal; $\mathrm{NA}=$ not applicable; $\mathrm{NT}=$ neuropsychological testing;

$\mathrm{OXC}=$ oxcarbazepine; $\mathrm{R}=$ right $\mathrm{VPA}=$ valproic acid $; \overline{\mathbf{x}}$ : mean.

$* \mathrm{p}<0.05$.

reflect a disruption of this downscaling. ${ }^{30}$ Our results support the adverse effects of ESES on neurodevelopment, perhaps explaining in part the highly diverse neuropsychological outcomes seen in children with perinatal stroke, in which lesion timing, size, and location are often very similar.
Age at both EEG and neuropsychological testing are important considerations that could not be controlled for in this study because of its retrospective design. The mean age at time of documented ESES in our study was 6.1 years (95\% CI, 4.3-7.9), which is similar to previously reported averages of 


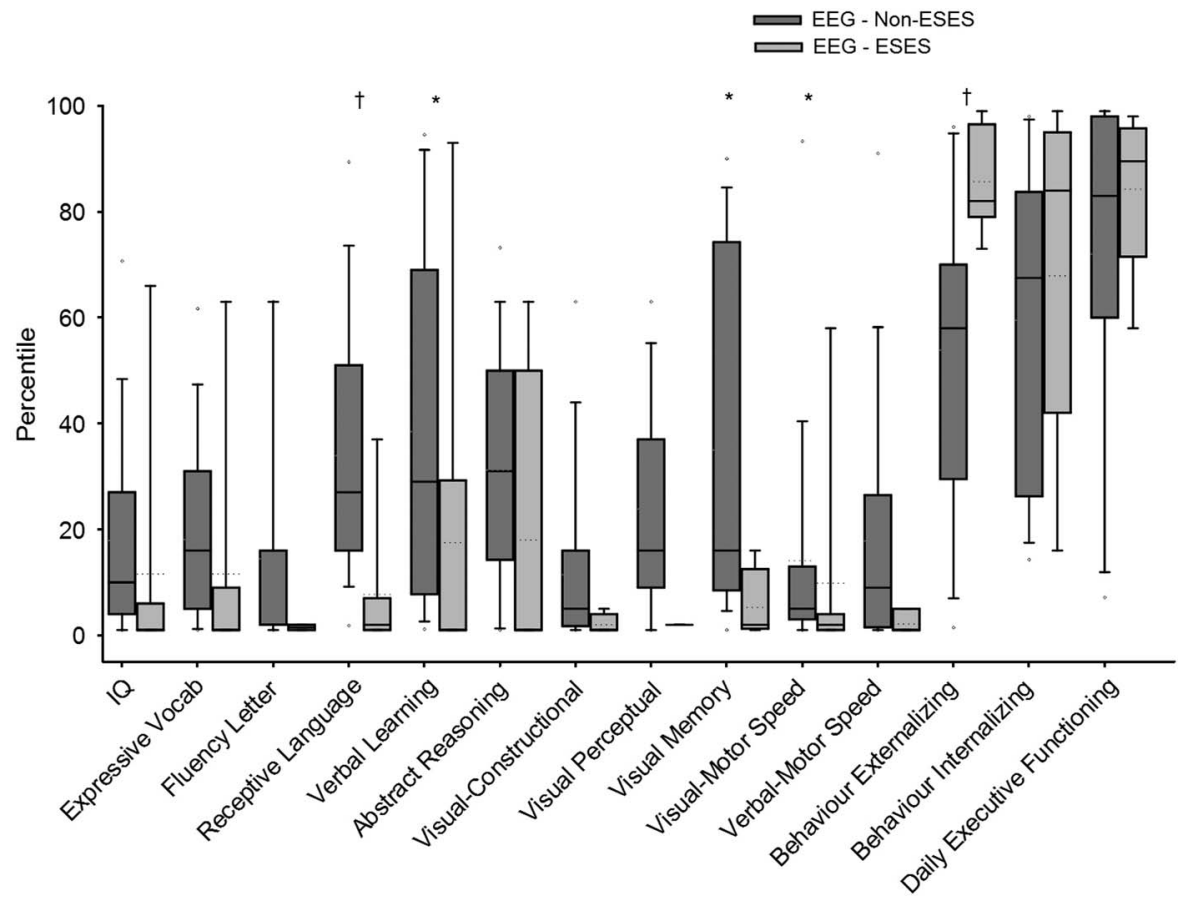

Figure 2: Neuropsychology results. Boxplot demonstrating neuropsychology domain scores. *Statistically significant differences. + Those domains that remain statistically significant after Bonferroni correction.

3.5 to 7.9 years. ${ }^{14,19,22,27}$ A recent meta-analysis suggests that ESES may be seen earlier in lesional patients with a mean of 2.0 years. ${ }^{16}$ Furthermore, ESES severity can vary over time and from one recording to another. ${ }^{31}$ A potential period of vulnerability and a critical time for investigation may exist. Children in whom there is an index of suspicion may benefit from evaluation at several time points during the ages of highest risk. Clinical suspicion would be maximal in any child demonstrating regression or plateauing of their development. However, because many children with arterial perinatal stroke have motor deficits

Table 3: Neuropsychology testing results

\begin{tabular}{|c|c|c|c|c|}
\hline Domain & $\begin{array}{c}\text { ESES } \\
\text { M (IQR) }\end{array}$ & $\begin{array}{l}\text { ESES absent } \\
\text { M (IQR) }\end{array}$ & p value & Effect size \\
\hline IQ & $1(1-6)$ & $10(4-27)$ & 0.090 & 0.307 \\
\hline Expressive vocabulary & $1(1-9)$ & $16(5-31)$ & 0.062 & 0.381 \\
\hline Letter fluency & $2(1-2)$ & $2(2-16)$ & 0.116 & 0.676 \\
\hline Receptive language & $1(1-7)$ & $27(16-51)$ & $0.002 *$ & 1.132 \\
\hline Verbal learning & $1(1-29)$ & $29(8-69)$ & 0.039 & 0.665 \\
\hline Abstract reasoning & $1(1-50)$ & $31(14-50)$ & 0.110 & 0.574 \\
\hline Visual-constructional & $1(1-4)$ & $5(2-16)$ & 0.079 & 0.655 \\
\hline Visual perceptual & $2(2-2)$ & $16(9-37)$ & 0.132 & - \\
\hline Visual memory & $2(1-13)$ & $16(9-74)$ & $\mathbf{0 . 0 3 3}$ & 1.101 \\
\hline Visual-motor speed & $2(1-4)$ & $5(3-13)$ & 0.090 & 0.209 \\
\hline Verbal-motor speed & $1(1-5)$ & $9(2-27)$ & 0.019 & 0.956 \\
\hline Behaviour externalizing $\dagger$ & $82(79-97)$ & $58(30-70)$ & $<0.001 *$ & 1.316 \\
\hline Behaviour internalizing $\dagger$ & $84(42-95)$ & $64(26-84)$ & 0.403 & 0.373 \\
\hline Daily executive functioning $\dagger$ & $89(72-96)$ & $83(60-98)$ & 0.801 & 0.614 \\
\hline
\end{tabular}

$\mathrm{M}=$ median percentile ranks; $\mathrm{IQR}=$ interquartile range.

The values in this table represent percentile ranks, with the range being from 1 to 99.

*Statistically significant following Bonferroni correction. Higher percentile ranks represent better cognitive abilities, except for those measures $\dagger$ where higher percentile ranks represent more behaviour problems. 
only, any early delays in nonmotor development would seem a reasonable indication for screening with sleep EEG. Neuropsychology evaluation of children with perinatal stroke focusing on language and behaviour domains might also help identify patients at risk.

In our study, participants with ESES were more likely to have a diagnosis of NAIS compared with APPIS. The presenting symptoms that differentiate these two syndromes may be association with future risk of epileptic encephalopathy. NAIS presents with symptomatic neonatal seizures in the vast majority, whereas most APPIS presents with motor asymmetry at 4 to 6 months of age. $^{32,33}$ In childhood stroke, acute seizures have been associated with the later development of epilepsy. ${ }^{34}$ Stroke side did not differ between the two groups. However, bilateral strokes were more common in the ESES group, which may indicate more severe injury and increased risk of developing epileptic encephalopathy. Identification of clinical markers associated with epileptic encephalopathy after perinatal stroke could inform screening strategies. Future volumetric studies could further determine how stroke size may influence epilepsy, EEG, and neurodevelopmental outcome.

Successful treatment of ESES is often difficult, and multiple approaches have been reported. A recent pooled analysis of 575 cases reported EEG or developmental improvement with AEDs (49\%), benzodiazepines (68\%), corticosteroids (81\%), and surgery $(90 \%) .{ }^{35}$ With focal, well-circumscribed lesions, perinatal stroke patients may make excellent surgical candidates. ${ }^{36}$ To date, minimal evidence has been published regarding specific treatment for lesional patients with ESES. Although cognitive impairments have been noted in patients with ESES, many patients continue to have significantly low cognitive function despite interventions. ${ }^{37}$ Timing of potential interventions may be important in improving developmental trajectories.

Our results demonstrate that, at time of neuropsychological testing, patients with ESES were more likely to be taking AEDs. It is impossible to determine the effect of medications in this context. Patients with epileptic encephalopathy may be more likely to be taking medication because of active seizures. The effect of the medication on cognitive outcome in this context is also unknown. The medications may contribute to cognitive slowing or improve cognitive outcome secondary to improved seizure control.

One of the limitations of this study is the exclusion of younger patients resulting from limitations of neuropsychological testing. Three patients with ESES could not be tested but, based on their cognitive status, would lower neuropsychological outcome scores for the ESES group. Neuropsychology evaluation in our centre is usually performed when there is suspicion of delays and may explain the lower than average scores in all domains for all patients. The degree of cognitive difficulty in the perinatal stroke population overall may be less severe than reported here.

Additional limitations in this study include a variable time lag between EEG and neuropsychological assessment in some cases, the retrospective design, the absence of a control group (normative data used instead), and initial EEG interpretation by several different electrophysiologists. We were unable to control for seizure frequency or epilepsy diagnosis because data were not available. The small sample size also prevented analysis of medication effects and other treatment interventions. The difference in age at time of EEG between the ESES and non-ESES groups may reflect that EEGs were performed outside the window for
ESES and patients with previous ESES might have been missed. This error would underestimate the difference in neuropsychology scores because patients with remote ESES would be included in the non-ESES group. This is more likely in patients with APPIS than NAIS who were slightly older at the time of their EEG.

This study was population-based with thorough capture of the stroke population, complete and detailed neuropsychological data, and precise definition of perinatal stroke syndromes using imaging classification. It contributes to an understanding of potential electrophysiology factors that may contribute to worse neurocognitive outcomes in patients with perinatal stroke and provides a clinically accessible tool to follow patients at risk. This knowledge justifies screening of at risk patients using sleepdeprived EEG to assess for ESES and neurocognitive assessments for planning appropriate learning and behavioural interventions. Future research should focus on the potential impact of treatment interventions.

\section{Disclosures}

The authors declare no potential conflicts of interest with respect to the research, authorship, and/or publication of this article.

\section{Statement of Authorship}

AM compiled the data, performed analysis, and wrote the final manuscript. WQ analyzed data and contributed to figures and reviewing the manuscript. HLC and BLB compiled and analyzed the neuropsychology testing and reviewed the manuscript. LB-E compiled and analyzed the electrophysiology data and reviewed the final manuscript. AK supervised data collection and analysis and critically reviewed and revised the final manuscript.

\section{REFERENCES}

1. Raju TN, Nelson KB, Ferriero D, Lynch JK. Ischemic perinatal stroke: summary of a workshop sponsored by the National Institute of Child Health and Human Development and the National Institute of Neurological Disorders and Stroke. Pediatrics. 2007;120:609-16.

2. Laugesaar R, Kolk A, Tomberg T, et al. Acutely and retrospectively diagnosed perinatal stroke: a population-based study. Stroke. 2007;38:2234-40.

3. Lee J, Croen LA, Backstrand $\mathrm{KH}$, et al. Maternal and infant characteristics associated with perinatal arterial stroke in the infant. JAMA. 2005;293:723-9.

4. Kirton A, deVeber G, Pontigon AM, MacGregor D, Shroff M. Presumed perinatal ischemic stroke: vascular classification predicts outcomes. Ann Neurol. 2008;63:436-43.

5. Lee J, Croen LA, Lindan C, et al. Predictors of outcome in perinatal arterial stroke: a population-based study. Ann Neurol. 2005;58: 303-8.

6. Golomb MR, Garg BP, Carvalho KS, Johnson CS, Williams LS. Perinatal stroke and the risk of developing childhood epilepsy. J Pediatr. 2007;151:409-13.

7. Westmacott R, MacGregor D, Askalan R, deVeber G. Late emergence of cognitive deficits after unilateral neonatal stroke. Stroke. 2009;40:2012-9.

8. Ricci D, Mercuri E, Barnett A, et al. Cognitive outcome at early school age in term-born children with perinatally acquired middle cerebral artery territory infarction. Stroke. 2008;39:403-10.

9. van Buuren LM, van der Aa NE, Dekker HC, et al. Cognitive outcome in childhood after unilateral perinatal brain injury. Dev Med Child Neurol. 2013;55:934-40. 
10. Ballantyne AO, Spilkin AM, Hesselink J, Trauner DA. Plasticity in the developing brain: intellectual, language and academic functions in children with ischaemic perinatal stroke. Brain. 2008; 131(Pt 11):2975-85.

11. Wusthoff CJ, Kessler SK, Vossough A, et al. Risk of later seizure after perinatal arterial ischemic stroke: a prospective cohort study. Pediatrics. 2011;127:e1550-7.

12. Wanigasinghe J, Reid SM, Mackay MT, Reddihough DS, Harvey AS, Freeman JL. Epilepsy in hemiplegic cerebral palsy due to perinatal arterial ischaemic stroke. Dev Med Child Neurol. 2010;52:1021-7.

13. Margari L, Buttiglione M, Legrottaglie AR, Presicci A, Craig F, Curatolo P. Neuropsychiatric impairment in children with continuous spikes and waves during slow sleep: a long-term follow-up study. Epilepsy Behav. 2012;25:558-62.

14. Kramer U, Sagi L, Goldberg-Stern H, Zelnik N, Nissenkorn A, Ben-Zeev B. Clinical spectrum and medical treatment of children with electrical status epilepticus in sleep (ESES). Epilepsia. 2009;50:1517-24.

15. Fernandez IS, Chapman KE, Peters JM, et al. The tower of Babel: survey on concepts and terminology in electrical status epilepticus in sleep and continuous spikes and waves during sleep in North America. Epilepsia. 2013;54:741-50.

16. Sanchez FI, Loddenkemper T, Peters JM, Kothare SV. Electrical status epilepticus in sleep: clinical presentation and pathophysiology. Pediatr Neurol. 2012;47:390-410.

17. Patry G, Lyagoubi S, Tassinari CA. Subclinical "electrical status epilepticus" induced by sleep in children. A clinical and electroencephalographic study of six cases. Arch Neurol. 1971;24: $242-52$.

18. Scheltens-de BM. Guidelines for EEG in encephalopathy related to ESES/CSWS in children. Epilepsia. 2009;50(Suppl 7):13-7.

19. Fernandez IS, Peters J, Takeoka M, et al. Patients with electrical status epilepticus in sleep share similar clinical features regardless of their focal or generalized sleep potentiation of epileptiform activity. J Child Neurol. 2013;28:83-9.

20. Berg AT, Berkovic SF, Brodie MJ, et al. Revised terminology and concepts for organization of seizures and epilepsies: report of the ILAE Commission on Classification and Terminology, 2005-2009. Epilepsia. 2010;51:676-85.

21. Kersbergen KJ, de Vries LS, Leijten FS, et al. Neonatal thalamic hemorrhage is strongly associated with electrical status epilepticus in slow wave sleep. Epilepsia. 2013;54:733-40.

22. Sanchez F, Takeoka I, Tas E M, et al. Early thalamic lesions in patients with sleep-potentiated epileptiform activity. Neurology. 2012;78:1721-7.
23. Losito E, Battaglia D, Chieffo D, et al. Sleep-potentiated epileptiform activity in early thalamic injuries: Study in a large series (60 cases). Epilepsy Res. 2015;109:90-9.

24. Sattler J. M. (2001). Assessment of children. Cognitive applications (4th ed.). San Diego, CA.

25. Galanopoulou AS, Bojko A, Lado F, Moshe SL. The spectrum of neuropsychiatric abnormalities associated with electrical status epilepticus in sleep. Brain Dev. 2000;22:279-95.

26. Paquier PF, Verheulpen D, De TX, Van BP. Acquired cognitive dysfunction with focal sleep spiking activity. Epilepsia. 2009; 50(Suppl 7):29-32.

27. Raha S, Shah U, Udani V. Neurocognitive and neurobehavioral disabilities in Epilepsy with Electrical Status Epilepticus in slow sleep (ESES) and related syndromes. Epilepsy Behav. 2012;25:381-5.

28. Cirelli C, Faraguna U, Tononi G. Changes in brain gene expression after long-term sleep deprivation. J Neurochem. 2006;98:1632-45.

29. Tononi G, Cirelli C. Sleep and synaptic homeostasis: a hypothesis. Brain Res Bull. 2003;62:143-50.

30. Bolsterli BK, Schmitt B, Bast T, et al. Impaired slow wave sleep downscaling in encephalopathy with status epilepticus during sleep (ESES). Clin Neurophysiol. 2011;122:1779-87.

31. Fernandez IS, Peters JM, Hadjiloizou S, et al. Clinical staging and electroencephalographic evolution of continuous spikes and waves during sleep. Epilepsia. 2012;53:1185-95.

32. Kirton A, Armstrong-Wells J, Chang T, et al. Symptomatic neonatal arterial ischemic stroke: the International Pediatric Stroke Study. Pediatrics. 2011;128:e1402-10.

33. Kirton A, Shroff M, Pontigon AM, deVeber G. Risk factors and presentations of periventricular venous infarction vs arterial presumed perinatal ischemic stroke. Arch Neurol. 2010;67:842-8.

34. Fox CK, Glass HC, Sidney S, Lowenstein DH, Fullerton HJ. Acute seizures predict epilepsy after childhood stroke. Ann Neurol. 2013;74:249-56.

35. van den $M B$, van $\mathrm{D}$, Sagi $\mathrm{L} \mathrm{V}$, et al. Treatment of electrical status epilepticus in sleep: a pooled analysis of 575 cases. Epilepsia. 2015;56:1738-46.

36. Battaglia D, Veggiotti P, Lettori D, et al. Functional hemispherectomy in children with epilepsy and CSWS due to unilateral early brain injury including thalamus: sudden recovery of CSWS. Epilepsy Res. 2009;87:290-8.

37. Japaridze N, Menzel E, von OG, Steinmann E, Stephani U. Risk factors of cognitive outcome in patients with atypical benign partial epilepsy/pseudo-Lennox syndrome (ABPE/PLS) and continues spike and wave during sleep (CSWS). Eur J Paediatr Neurol. 2014;18:368-75. 